\title{
The State and the Demand for Security in Contemporary Societies
}

\author{
by Raymond Barre *
}

Economic activity, like all human activity, is marked by uncertainty and exposed to risk. All economic calculations aim at limiting the risk or attenuating its possible unpleasant consequences.

The behaviour of the actors on the economic scene is motivated to a large extent by the desire for security. The extent of the uncertainty and the fear of excessively great risks can be a brake on action. Thus economic calculations must determine a point of equilibrium between risk and security.

Economic activity is carried on in an environment governed by collective and individual mentalities, social rules, the state of technology and the policy of the State. The conditions under which risk is present and under which it can be accepted are thus variable. Society, too, is led to seek a point of equilibrium between risk and security and to establish collective machinery for protection against and coverage of risks.

At a low level of development of the economy, individual savings appear as the first form of insurance against risks ; they are often in kind and constitute a guarantee of survival. In a monetarised economy, liquid funds for transactions and reserves enable the unexpected to be met.

But in modern economies there are specific institutions which have the function of affording individuals and enterprises coverage of the risks against which they wish to insure.

The demand for insurance has constantly become more diversified : the growing complexity of activities has led to a multiplication of risks; the rise in income has enabled a greater share of resources to be allocated to meeting the need for insurance. The insurance offered has sought to respond to these needs, both of individuals and of enterprises.

But the changes in mentalities and societies have brought about a phenomenon which is now basic in industrialised societies : extensive intervention by the State, which sets up insurance systems founded on the principle of national solidarity.

* Professor at the University of Paris. Former President of the Geneva Association and former Prime Minister of the French Government. 
It is the aspects and consequences of this phenomenon that $I$ wish to consider briefly here, because it raises problems of great importance :

- the problem of the fields covered by public insurance ;

- the problem of the financing of this insurance and of its effects on the economy and on public finances;

- the problem of the relationships between the public insurance institutions and the private institutions which hitherto carried out this function.

However, over and above these problems there is a fundamental question which, in my view, already seems to be arising in many countries. I will put it in the following way :

We are living in a world where uncertainty is growing and risks are becoming ever more extensive. At the same time, we note an upward trend in the demand for security. To what extent can the demand for security be met by the State without slowing down or hindering the adaptations made necessary and inevitable by the farreaching changes in the world?

In the final analysis, this question concerns a choice of society. Are we heading towards a society of assistance, where the State takes over the citizens' risks or do we want to preserve a society of freedom and responsibility, where the risks are shared between the State, private insurance institutions and the citizens themselves? In other words : in tomorrow's society is insurance to be a collective or a collectivist effort ?

To observe contemporary societies will suffice to measure the importance of this question, which becomes all the more acute in that it arises in a period of what seems a lasting crisis. The replies remain confused and hesitant ; in this respect both the Reagan experiment in the United States and the socialist experiment in France represent opposing and symbolic types of reply which cannot yet be definitively evalued, even if, in both cases, success does not seem certain.

Going beyond these specific situations, I would like to put forward here some reflections on what $I$ will call the need for security in contemporary societies and the means of meeting this need in the context of a progress-oriented society.

The aspiration towards security, long individual, became an ever more intensive collective aspiration following the Great Depression of the 1930s.

The spectacle of millions without jobs and without incomes, unable to cover the risks of existence, promoted the search for machinery capable of guaranteeing the individual assistance from the community in the most difficult circumstances arising during his existence. With Beveridge there came into being after the Second World War the modern concept of Social Security, the generalised application of which led to the "Welfare State". Such application was greatly facilitated and promoted by the long period of prosperity experienced by the Western world from 1950 until the 1970s. Rapid growth of the economy promoted the regular formation of a surplus which permitted both an increase in individual incomes and a wide re-distribution of income. All governments, under the pressure of public opinion or taking a generous approach 
to their action, provided growing coverage of risks and sought to afford their citizens a sort of general guarantee of security.

The social security systems insure the individual against the contingencies of :

- sickness ;

- family life ;

- old age.

Other systems of social protection cover the risk of unemployment.

Protection, afforded first to wage earners, has tended to be extended to all citizens.

Moreover, there is a tendency, in certain circumstances, for the economic risk linked with the activities of enterprises, and covered for a long time by the enterprises themselves or by private insurance institutions, to be taken over by State mechanisms. The State provides export-credit insurance ; to counter international monetary instability it provides exchange guarantees. When an enterprise occupying an important place in the national or regional economy finds itself in difficulties the State provides it with assistance in the form of subsidies, orders or loans on advantageous terms, doing this for various reasons, the most important being employment. The logic of a private economy based on the acceptance of risk is gradually yielding to another logic : that of the public economy. Finally, in certain cases, the income of an entire category of economic agents - farmers - is guaranteed against the hazards of harvests and fluctuations in agricultural prices.

This considerable extension of the protection against risk involves a high cost for the economy.

It entails, first, an explosion of public expenditure and, more particularly, of social expenditure. From 1965 to the end of the 1970s the ratio public expenditure / GDP recorded an increase of over 10 percentage points in the leading industrialised countries, in particular in the United Kingdom, Germany, France, Italy, Netherlands, Norway, Sweden and Switzerland.

The growth in expenditure entails, secondly, a massive increase in income tax and social security contributions. In the OECD countries as a whole tax pressure increased from $28 \%$ in 1965 to $36.6 \%$ in 1980.

The burden on the productive economy represented by the financing of security has several consequences :

- a more rapid increase in prices, inflation being a way of passing on to consumers in general the costs weighing on the productive sectors. At the end of the 1940s Colin Clark took the stand that inflation would become inevitable when tax pressure exceeded $25 \%$. We have now gone well beyond that ;

- an increase in unemployment due to over-rapid increase in production costs, which incorporate the social contributions paid by enterprises ;

- growing inflexibility of the economy, whose resources become less mobile because of income guarantees and are employed in a less efficacious manner ;

- a weakening of the impetus to work and to save ;

- a greater propensity for those active in the economy to engage in clandestine activities which escape taxation. 
Thus, economic growth, which is essential to finance expenditure on security, is slowed down. The economy enters a stage of stagnation, accompanied by inflation and unemployment. A cumulative process of disequilibrium starts to operate: the growth in charges causes a rise in unemployment which, in turn, brings an increase in public expenditure and a further surge of inflation.

At the present time this unfavourable evolution of the economy is taking place in a world facing very extensive collective risks :

- risks linked with a high degree of monetary instability, which since 1971 have caused the disappearance of the international monetary system and the coming about of floating exchange rates ;

- risks linked with the vulnerability of the international financial systems, due to the massive indebtedness of some developed or developing countries, and with the dangers of the recycling of international capital ;

- risks linked with the great intensification of international competition, which calls for profound changes in the industrialised economies and, to this end, for greater resource mobility and more ardour for productive effort.

The desire for security tends to produce different reactions to these collective risks :

- the search for a guarantee against monetary risks by price-linking at the domestic level and by "competitive devaluation" in the field of exchange rates ;

- recourse to protective measures in order to safeguard economic activity and employment.

It thus appears that the constant effort to achieve a balance between risk and security, on which the vigour and progress of the economy depends, is being compromised by the growing importance attached to meeting the individuals'need for security. The danger lies in a decrease in the over-all productivity of the economy, a fall in living standards and ever more comprehensive State regulation of economic activities.

Beveridge proclaimed: "Full employment in a free society". We risk finding ourselves in a different situation : "unemployment in a closed and controlled society". Can such a process be stopped or is it irreversible ?

Observation of contemporary societies leads at present to two findings :

- first, individuals, who have enjoyed a regular growth of their income and a steady improvement of their living standards during the past twenty years, do not seem ready to accept an economic downswing; they know that the countries where economic and social activity are closely regulated are those where living standards are lowest even if employment and income security and social protection are largely provided for there ;

- second, they would not accept changes in the system of social protection, as this would appear to be a return to the past or a step backward.

Thus, from the viewpoint of economic and social policy, the problem is to find a point of equilibrium at which the level of social protection remains compatible with 
respect for the basic balance of the economy and the safeguarding of the stimulus to growth and progress. What is involved is a problem of "risk management" at the level of the national collectivity.

Within the limits of this talk it would not be possible for me to deal fully with this question. I thus propose to confine myself to outlining solutions which seems to me practicable from the political and social viewpoints.

1. The State must, as a first step, seek to reduce the collective economic risks burdening the citizens.

The most serious of these risks - the one which has the most far-reaching effects on the collectivity - is inflation. Inflation causes unemployment, discourages saving, reduces the purchasing power of incomes and retirement pensions and threatens the international value of the currency.

Combating inflation cannot be reduced to controlling, even drastically, the supply of money. The United States experience, like that of other countries, shows that monetary policy loses its efficacity if it is not used in combination with budgetary policy. The situation facing contemporary societies is so dramatic because of the extent of their budgetary deficits, which result in an increase of Treasury pressure on the capital market and in causing a sharp increase in interest rates, which slows down investment.

A lasting slowdown of rises in prices and a return to economic growth backed by investment can be achieved in the Western economy only by implementing a budgetary policy aimed at :

a) putting an end to the rapid and steady progression of public expenditure, which should grow less rapidly than the GNP;

b) bringing the rate of progression of social expenditure down to that of the GNP ;

c) employing the results achieved by mastering social and public expenditure to reduce the levies on private income and the charges borne by enterprises.

The general situation of the Western economies imposes henceforth the need to reduce expenditure in order to relieve taxation instead of systematically increasing taxes in order to cover expenditure.

2. The State, as a second step, must limit the extension of coverage of risks through national solidarity and facilitate, alongside the protection afforded by the community against the basic risks faced by individuals, the development of risk-covering machinery based on group insurance or individual insurance.

The thinking which justifies such an orientation is that, at the high level of income existing in the industrialised societies, the individual's participation in social protection can be increased in relation to the share hitherto borne by the State. Obviously State intervention would remain essential in the case of the least favoured.

Three examples may serve to illsutrate this orientation :

1. As regards unemployment benefits, the financial machinery employed in some countries enables a worker who has lost his job to receive for a fairly long period an allowance almost equal to what he was earning previously; nor is the unemployed person under any obligation whatever as regards accepting a new job. 
Abuse of these provisions has led, on the one hand, to a situation where, in a period when unemployment exists, employers cannot find the manpower they need, and, on the other hand, to the development of clandestine work.

The need thus appears to correct these anomalies by two means :

- first, a scale of unemployment benefit which decreases sharply over the period during which it is paid ; this is the path on which France had embarked in 1979, after a benefit equal to $90 \%$ of the previous wage had been paid for several years ;

- second, imposing an obligation on the unemployed person to accept, after a certain time limit, a job offered to him : this is the path on which the Government of the Federal Republic of Germany embarked very recently.

2. As regards sickness insurance, it appears more and more desirable, in addition to being a justified policy of achieving economies, to take action in respect of the conditions of reimbursement of costs and to increase the individual's participation in the financing of these costs.

A formula already employed is that whereby the insured person bears a share of the cost, a share which may vary depending on the type of benefit.

Another formula would be modulation of the reimbursement on the basis of income or, to use another expression, personalised social insurance.

In both these cases the most important risks would continue to be fully covered by the collectivity. In both cases it would be for the individual to finance, by means of a special contribution, any more extensive coverage that he might desire. Thus, there has been noted in recent years an increase in voluntary sickness insurance, supplementing social security.

3. As regards retirement-pension systems, the problem often posed is that of the choice between the distributive system and the capitalisation system. Recent studies have, however, shown that there is no justification for putting forward a choice between the two systems ; what is needed is to seek to establish, for the various categories of persons, what share of the financing of the pension can be borne by each system.

The level of transfer to retired persons of contributions by means of distribution can be determined by the State in the light of considerations of a financial, economic and demographic order ; the supplementary pension that certain persons may wish to receive can then be provided by means of a system of capitalisation.

This capitalisation can be individual, at least for those who dispose of the necessary financial resources.

It can be collective, achieved through capitalisation institutions, which can offer individual persons attractive procedures for contractual saving, and which help in the long-term savings necessary for the economy.

The foregoing analysis reveals the kinds of prospects that can open up for systems of social protection in modern societies.

It is clear that States are henceforth constrained to set a limit on the progression of expenditure to cover risks; even if they did not wish this, the objective economic 
conditions would force them to do so, unless they change the way in which the economy and society are organised.

To satisfy the individual's need for security it would seem appropriate, on the one hand, to allow for a greater degree of individual responsibility in the choice of the desirable level of protection and the protection devices that can be used and, on the other hand, to develop supplementary non-State mechanisms for social protection.

The insurance companies can play a very important role in this respect, both as regards offering well-adapted products capable of meeting the demand of individuals or of groups and as regards the management for the benefit of the national economy of the savings resources they collect.

The path of the future does not lie in a choice between public logic and private logic in regard to social protection but in collective action in which the public sector and the private sector are associated and which takes account of both the advantages and the limitations that each presents.

Such should be one of the forms of social innovation which our societies need for their stability and their development. 